\title{
END-PRODUCT QUALITY CHARACTERISTICS AND CONSUMER RESPONSE OF CHICKPEA FLOUR-BASED GLUTEN-FREE MUFFINS CONTAINING CORN STARCH AND EGG WHITE
}

\author{
MARÍA DOLORES ALVAREZ ${ }^{1,3}$, BEATRIZ HERRANZ ${ }^{1}$, MARÍA JOSÉ JIMÉNEZ ${ }^{2}$ and \\ WENCESLAO CANET ${ }^{1}$
}

${ }^{1}$ Department of Characterization, Quality, and Safety, Institute of Food Science, Technology, and Nutrition (ICTAN-CSIC), José Antonio Novais 10, 28040 Madrid, Spain.

${ }^{2}$ Sensory Analysis Service Unit, Institute of Food Science, Technology and Nutrition (ICTAN-CSIC), José Antonio Novais 10, 28040 Madrid, Spain.

${ }^{3}$ Corresponding author.

TEL: +34 915492300.

EMAIL: mayoyes@ictan.csic.es

Running title Corn starch-Egg white enriched chickpea flour gluten-free muffins 


\section{ABSTRACT}

The objective of this work was to study changes in technological characteristics and sensory properties of gluten-free muffins when using chickpea flour (CF) alone and/or with partial CF replacement by corn starch (CS). The effect of partial whole egg replacement by egg white (EW) was also investigated. Four different CF:CS ratios (100:0, 75:25, 50:50, and 25:75) were used in formulations with and without incorporated EW, and compared with wheat flour (WF) muffins (0:0). Muffins prepared from CF alone had lower hardness, springiness, cohesiveness, chewiness, and resilience than control ones. However, reducing protein content by CS addition significantly increased texture profile analysis (TPA) parameters of muffin crumb. Muffins prepared with 25:75 ratio had a structure with springiness similar to muffins made with WF but were too hard. Reducing whole egg content by partial replacement with EW also significantly increased muffin hardness. Flash profile (FP) performed by consumers showed a clear discrimination of muffins according to CF:CS ratio. Muffins containing both CF and CS at 50:50 ratio had the same high overall acceptability $(\mathrm{OA})$ and purchase intention $(\mathrm{PI})$ as gluten ones. Gluten-free CF-based muffins of satisfactory quality can be manufactured by CS incorporation, either with or without EW.

\section{KEYWORDS}

Chickpea flour, gluten-free muffin, egg white, corn starch, texture, flash profile 


\section{PRACTICAL APPLICATIONS}

By decreasing and increasing protein and starch contents of chickpea flour (CF) by incorporation of corn starch (CS), muffins formulated from a combination of CF and CS at different CF:CS ratios, either with or without partial replacement of whole egg with egg white (EW), result in high-quality muffins with similar technological and sensory characteristics to those of their gluten counterparts. Sensory overall acceptability (OA) and purchase intention (PI) of muffins made with a 50:50 ratio did not differ significantly from those of the controls. These findings will benefit celiac population, while promoting the value and utilization of pulses through muffins. 


\section{INTRODUCTION}

The growing demand for gluten-free products is caused by the increasing number of patients diagnosed with gluten intolerance (Matos et al. 2014; Shevkani et al. 2015; Witczak et al. 2016). The main functional gluten-free ingredients used in their manufacture are starches, refined nonwheat flours, and pseudocereals, and they are generally not enriched or fortified (AlvarezJubete et al. 2010). Consequently, they often have lower quantities of proteins, B vitamins, iron, and fiber than their gluten-containing counterparts (Gularte et al. 2012a). Furthermore, many gluten-free products available on the market are of poor technological quality, exhibiting low volume, poor color, and crumbling crumb (Matos et al. 2014).

Sweet baked products, particularly muffins, are highly appreciated by consumers, especially by children, because of their soft texture and characteristic delicious taste (Martínez-Cervera et al. 2012a,b; Dizlek, 2015). However, limited research has been carried out to develop glutenfree muffins. Matos et al. (2014) studied the effect of various proteins on the quality of rice muffins; egg white (EW) protein and casein increased specific volume in comparison with their wheat counterparts. Shevkani and Singh (2014) showed that gluten-free muffins comparable to those with gluten could be prepared from corn starch (CS) by incorporating protein isolates from kidney bean, field pea, and amaranth. TPA showed that corn flour muffins made using egg yolk granules were harder than ones made with whole egg yolk (Marcet et al. 2015).

2016 was designated as the International Year of Pulses (IYP, 2016), aiming to position pulses as primary sources of protein and other essential nutrients, leading to dietary uptake (Singh et al. 2015). Chickpea (Cicer arietinum L.) is a legume rich in protein, dietary fiber, carbohydrates, folate, and trace minerals (Aguilar et al. 2015). However, gluten replacement 
constitutes a technological challenge, owing to deficiencies such as low volume and lower nutritional value in comparison with wheat counterparts (Tsatsaragkou et al. 2015). Making chickpea flour (CF)-based muffins may improve nutritional value, but end-product quality characteristics should also be considered. Both quality and sensory characteristics of muffins are important for consumer overall acceptance (Dizlek 2015). Herranz et al. (2016) studied the effect of adding biopolymers on physical and sensory properties of CF-based muffins. Muffins with xanthan gum added at $1 \%$ had similar hardness to wheat gluten ones, but all the formulated CF-based muffins had worse technological and sensory characteristics than gluten counterparts.

The role of the consumer in determining the market success of a novel product is of maximum importance. Flash Profile (FP) is a quick sensory profiling technique based on a combination of free choice profiling and comparative evaluation of a whole product set, which can be used as a tool in consumer research with the assistance of an untrained panel (Albert et al. 2011). Assessors are asked to make their own list of sensory characteristics to describe differences among samples, and then rank the samples for each listed attribute.

Taking all this into account, the first aim of this work was to research the effect of combining CF with CS at different CF:CS ratios on mechanical, physicochemical, and structural characteristics of CF-based muffins. EW was also evaluated as a partial substitute for whole egg. A second aim was to assess the use of FP methodology to ascertain their sensory properties as perceived by consumers.

\section{MATERIALS AND METHODS}




\section{Materials}

The materials used in this study were wheat flour (WF), CF (C. arietinum, cv. Castellano) (moisture content $14.0 \mathrm{~g} / 100 \mathrm{~g}$, protein $19.4 \mathrm{~g} / 100 \mathrm{~g}$, crude fiber $15 \mathrm{~g} / 100 \mathrm{~g}$, total fat $5 \mathrm{~g} / 100 \mathrm{~g}$, total carbohydrate $55 \mathrm{~g} / 100 \mathrm{~g}$ ), composition provided by García del Valle flour milling company (Soria, Spain), CS (MAIZENA ${ }^{\circledR}$, crude fiber $1 \mathrm{~g} / 100 \mathrm{~g}$, total fat $<0.5 \mathrm{~g} / 100 \mathrm{~g}$, protein $<0.5 \mathrm{~g} / 100 \mathrm{~g}$, total carbohydrate $86 \mathrm{~g} / 100 \mathrm{~g}$ ), composition provided by Unilever España, S.A. (Barcelona, Spain), pasteurized liquid EW and pasteurized liquid whole egg (Ovopack ${ }^{\circledR}$, Seville, Spain), ultrahigh temperature whole milk (Pascual, Burgos, Spain), refined sunflower oil (Koipesol, Madrid, Spain), sucrose (AB Azucarera Iberia S.L., Madrid, Spain), and baking powder (Royal ${ }^{\circledR}$, Madrid, Spain).

\section{Muffin Making Procedure}

Ten baked muffins were prepared from five batter formulations, at different CF:CS ratios, made with and without incorporated EW (Table 1). Samples with incorporated EW contained both EW and whole egg at a ratio of 70:30, whereas samples without added EW contained whole egg alone. There were two control formulations with WF alone (0:0 ratio), two others prepared by replacing all of the WF with CF (100:0 ratio), and six more CF-based formulations made by partially replacing CF with CS, with CF:CS ratios of 75:25, 50:50, and 25:75. Individual codes and $\mathrm{CF}: \mathrm{CS}$ ratios of the muffin formulations are summarized in Table 1 . Muffin batters were prepared as described by Herranz et al. (2016), with some modifications. The batters were all kept at $25^{\circ} \mathrm{C}$ for 60 min before baking. 
In this study, exactly $40 \mathrm{~g}$ of batter was dosed into each $55 \mathrm{~mm}$ diameter $\times 30 \mathrm{~mm}$ high paper mold. Fifteen molds were arranged in three rows of five muffins on a baking tray and baked for $25 \mathrm{~min}$ at $185{ }^{\circ} \mathrm{C}$ in a Memmert (UFE 400) electrical oven (Schwabach, Germany) preheated to that temperature for $45 \mathrm{~min}$. After baking, the muffins were left to cool at $20^{\circ} \mathrm{C}$ for $1 \mathrm{~h}$. Then they were packed in polyethylene bags and stored at $20^{\circ} \mathrm{C}$ for an additional $24 \mathrm{~h}$ until end-product quality determinations and/or sensory analysis were conducted. Baked muffins from each formulation were prepared in at least five independent batches, on different days.

\section{Instrumental Muffin Crumb Texture Measurements}

Instrumental parameters were measured with a TA.HDPlus Texture Analyser (Stable Micro Systems Ltd., Godalming, UK) provided with Texture Exponent software (version 6.1.9.0) and equipped with a $50 \mathrm{~N}$ load cell and a $100 \mathrm{~mm}$ diameter aluminum plate (P/100). The muffins were cut horizontally at the height of the mold, the upper half was discarded, and the lower half was removed from the mold. TPA tests were carried out directly on the complete crumb lower half. Muffin crumbs were double compressed to $50 \%$ of the original height, with a rest period of $3 \mathrm{~s}$ between cycles. The trigger force was $0.05 \mathrm{~N}$ and the test speed was $2 \mathrm{~mm} / \mathrm{s}$. The force-time curves gave the three primary textural parameters: hardness (Hard, N), springiness (Spr, dimensionless), and cohesiveness (Coh, dimensionless), as well as chewiness (Chew, N) and resilience (Res, dimensionless). Definitions of TPA parameters are given elsewhere (Baixauli et al. 2008; Singh et al. 2015). Five muffins per formulation were evaluated. All formulations were measured in duplicate (two different preparations on different days). 


\section{Other Muffin Physicochemical Characteristics}

Collapse $(\mathrm{mm})$, specific volume $\left(\mathrm{cm}^{3} / \mathrm{g}\right)$, water activity $\left(a_{w}\right)$ of the crumb, and color of either muffin crust or crumb were determined in accordance with the methodology used in previous works (Alvarez et al. 2016; Herranz et al. 2016). Three replicates of each determination were made with muffins prepared on three different days.

\section{Microstructural Characteristics of Baked Muffins}

Baked muffins were observed using an L2-S8 APO Stereomicroscope (Leica Microsystems, Wetzlar, Germany) with a magnification of 1.5×. Micrographs were taken with an Optika (Model Optikam B5) color digital camera coupled to Optika Vision Lite software. Microstructure was also examined using a Jeol JSM-6500F (Jeol Ltd., Tokyo, Japan) field emission scanning electron microscope (SEM) with a resolution varying from $1.5 \mathrm{~nm}(15 \mathrm{kV})$ to $5.0 \mathrm{~nm}(1 \mathrm{kV})$. Samples were air dried, then mounted and sputter-coated with Au (200 ^̊ approx.) in an SPI diode sputtering system metallizer. Micrographs at 200 and $25 \times$ magnification are shown.

\section{Sensory Evaluation and Consumer Perceptions}

FP was carried out by 30 untrained students and employees of ICTAN-CSIC (aged 25-64 years). FP does not demand a specific participant training stage, and in this case it consisted of two sessions in which six muffins (at 0:0, 100:0, and 50:50 ratios with and without incorporated EW) were presented simultaneously. During the first session the consumers were given an explanation about the procedure and asked to taste and examine the muffins in order to generate their own individual list of attributes, which had to be sufficiently discriminating to 
allow ranking of the samples. Consumers were instructed to avoid hedonic terms. In the second session they assessed the six muffins, ranking them from "least" to "most" for each generated attribute (ties were allowed). They were also asked to score overall acceptability (OA) and other perceptions, such as intensity of satiating capacity (ISC) and purchase intention (PI), for each muffin, using nine-point hedonic scales ranging from 1 (dislike extremely, not very satiating, I would definitely not buy, respectively) to 9 (like extremely, very satiating, I would definitely buy, respectively).

\section{Statistical Analysis}

Two-way mixed-analysis of variance (ANOVA) was performed to study separately the main effects (CF:CS ratio and incorporation of EW) and the interaction effect (CF:CS ratio $\times \mathrm{EW}$ ) on the instrumental measurements. One-way ANOVAs comparing the means within the same EW level (with and without EW) for the various CF:CS ratios (0:0, 100:0, 75:25, 50:50, and 25:75), and within the same CF:CS ratio for both EW levels, were performed. Minimum significant differences were calculated using Fisher's least significant difference (LSD) test at 1\%.

For the FP data, individual matrices for each panelist (samples $\times$ attributes) were built to enter muffin rankings. A generalized Procrustes analysis (GPA) was performed on the 30 matrices to obtain sample and attribute configurations. To identify the muffins and terms most closely related to the OA, ISC, and PI scores, a multiple factor analysis (MFA) was performed using these three perceptions as supplementary variables.

OA, ISC, and PI scores were also analyzed using one-way ANOVAs, comparing means within the same EW and CF:CS ratio levels by the LSD test at 5\%. Finally, sensory data from FP were 
analyzed jointly with instrumental measurements using MFA taking into account only those attributes generated by consumers that were related to muffin texture and appearance characteristics. Regression vector (Rv) coefficient was used to compare agreement in the structure of the configurations determined by consumers and instrumental spaces.

Data analyses were carried out with Statgraphics Plus 5.1 (Statistical Graphics Corporation, Inc., Rockville, MD, USA) and XLSTAT add-in for Microsoft Excel software version 2012 (Addinsoft, Paris, France).

\section{RESULTS AND DISCUSSION}

\section{Instrumental Texture of Baked Muffin}

Both CF:CS ratio and EW main effects significantly $(P<0.01)$ affected muffin crumb texture (Table S1), and interaction between effects was also significant except for Spr from the TPA test. EW had a more significant effect than CF:CS ratio (higher $F$ values) on Hard and Chew values, while the opposite was true for Spr, Coh, and Res.

Mean textural properties of the baked muffins from TPA tests are shown in Table 2. The two muffins containing the highest CS concentration (25:75 ratio) had the highest Hard values, showing that higher starch and lower chickpea protein contents increased the force needed for compression. Substitution of CF by CS may have reduced the number of air pockets and increased their size; therefore the compression force increased, resulting in a firmer texture [Table 2 here]. Tsatsaragkou and others (2015) showed that initial moisture content was also significant in crumb firmness of cakes. In this study, initial moisture contents were 13,10 , and $9 \%$ for WF, CF, and CS, respectively. Therefore, the lower Hard of the 100WF-EW sample may be 
attributed to its higher moisture content. The variation observed for different CF:CS ratios may also be due to their different protein concentrations, their degree of interaction with water, and conformational characteristics (Chandra and others 2015). Functional properties of flours (WF and CF) and CS were analyzed (data not shown), and CF had the highest water absorption and water-holding capacities, which can be attributed to its higher protein content. Moreover, the texture measurements were carried out $24 \mathrm{~h}$ after baking, and it is well known that higher starch/starch complexes favor starch retrogradation (Aguilar and others 2015).

Regarding the EW effect, the Hard of all the CF-based crumbs with added EW was significantly higher than that of the control, whereas without EW there were no significant differences between crumb Hard values of 100WF, 100CF, and 25CF75CS muffins. Therefore, changes in crumb Hard with CF:CS ratio were less significant in muffins made with whole egg alone. EW proved effective to obtain firmer muffins than the gluten sample, almost doubling the hardness when $75 \%$ of CF was replaced with CS in gluten-free muffin.

Spr is a desirable muffin property associated with a fresh, elastic, aerated product (Shevkani and Singh 2014), and, in the case of muffins, high Spr values are linked to high quality (Sanz et al. 2009). The Spr of the crumb was also affected by the degree of CS inclusion in the muffin (Table 2). Interestingly, in CF-based muffins with or without added EW, the increase in Spr was linear with CF replacement, and the highest Spr values corresponded to the highest CS concentration. The values at 25:75 ratio were the same as for the gluten muffins, whereas both muffins made with CF alone exhibited the lowest Spr values, which is associated with protein aggregation during baking (Wilderjans et al. 2010) and low starch content. The authors just cited showed that aggregated protein in cake crumb is related to $\mathrm{Spr}$, as the combination of a protein 
network, formed during baking, with a starch gel, formed during cooling, results in a stable structure with more resistance to collapse. Similarly, navy bean flour cakes had lower crumb Spr than WF cake (Singh et al. 2015). Similarly, in both rice- and CS-based gluten-free muffins, the incorporation of different protein sources significantly increased this textural parameter (Matos et al. 2014; Shevkani and Singh 2014). The decrease in Spr was associated with a decrease in the number of muffin air bubbles and the presence of a denser matrix (Baixauli et al. 2008). However, no positive relationship between the number of air bubbles and Spr was found among different resistant starch muffins (Sanz et al. 2009).

Therefore, in this study, in comparison with muffin made with CF alone, reduced chickpea protein content and increased CS concentration would appear to form an elastic network with gelatinized starch similar to the muffin structure formed by gluten in WF. Furthermore, negative correlations were observed between both Spr and RES and percentage of protein in final muffins, whereas it seems that the CS gel influenced crumb Hard or firmness.

Coh values were significantly lower in all the CF-based muffins than in the two controls. WF and CF alone produced the most and the least cohesive muffins, respectively, although in muffins either with or without EW there was an overall increase in Coh with increased CS and reduced CF incorporation, a factor that can be associated with the increased Spr, and that would result in greater elasticity of the samples with reduced chickpea protein. Chew values followed the same trend as Hard, Spr, and Coh values (Table 2). For muffins with and without added EW, Chew also increased with CS incorporation, making them more difficult to chew, the highest value being for muffins with $75 \mathrm{~g}$ CS incorporation and the lowest one for 100CF-EW 
muffins. In contrast, in the muffins without EW the control muffin showed significantly higher Chew, indicating that all the CF-based muffins were easier to chew than the gluten one.

For Res, the ratio of recoverable energy as the first compression is relieved (Singh et al. 2015), the two gluten muffins also showed the highest values, whereas the two muffins made with CF alone had the lowest ones. Generally, denser masses with lower numbers of gas cells obtain lower Res values, implying that it will take more time for the muffin structure to recover after compression (Martínez-Cervera et al. 2012a). Replacement of CF with CS had a significant effect on Res, increasing with CS incorporation. Results showed that reducing chickpea protein content by addition of CS significantly reduced the differences between Spr, Coh, and Res of gluten-free and gluten muffins. Similarly, it has been reported that navy bean flour with protein content adjusted to the level of WF has potential as a healthy alternative in gluten-free cakes (Singh et al. 2015).

\section{Physicochemical Characteristics of Baked Muffin}

Two-way ANOVA showed that either CF:CS ratio or EW had a significant effect on the collapse, specific volume, and water activity of the crumb (Table S2), with the EW incorporation effect on these physicochemical properties being more significant (higher $F$ values). Furthermore, the $\mathrm{CF}: \mathrm{CS}$ ratio effect on these parameters was dependent on the presence or absence of EW, except for specific volume. With regard to color parameters of the muffin crusts and crumbs, all color parameters were significantly affected by CF:CS ratio. In contrast, only the $a^{*}$ parameter of the crumb was significantly affected by EW incorporation (Table S2), whereas interaction between effects was only not significant for the crumb $b^{*}$ parameter. 
Mean values of the physicochemical properties of the baked muffins are shown in Table 3 [Table 3 here]. Muffin collapse decreased significantly when both CS and EW were incorporated. Therefore, the combination of CS and EW probably gave some strength to the network during thermal treatment, and that counteracted the higher collapse observed with WF or CF alone. As found for wheat gluten (Luo et al. 2016), it is also possible that egg albumin strengthens the chickpea protein network to hold the CS during cooking. However, muffins made with a 25:75 ratio and without EW had significantly lower collapse than the others, indicating that a consolidated 3D network was formed by interaction of CS granules with other components of the formulation, such as lipids and proteins from chickpea. The incorporation of native CS in the batter matrix promoted interactions with other components via hydrogen and electrostatic bonds (Guadarrama-Lezama et al. 2016).

In muffins with EW, replacing WF with any CF:CS ratio resulted in lower specific volume, but only muffins made with the $75: 25$ ratio had a specific volume significantly lower than that of the control muffin. Surprisingly, in muffins without added EW, those made with CF alone had the lowest volume, which might be due to an increase in batter viscosity (data not shown) that reduced expansion in the oven (Gularte et al. 2012a), as well as the larger particle size of CF compared with WF and CS (data not shown). In addition, in the absence of EW, larger muffin specific volumes were obtained with lower chickpea protein and higher CS contents (Table 3), which is attributable to CS reducing the viscosity of the batter and aiding air incorporation during batter mixing, thus achieving an improvement in the height and volume of the final product. In muffins prepared with amaranth and buckwheat flours (Dizlek 2015), specific volumes of muffins with batter weights from 50 to $80 \mathrm{~g}$ were lower, ranging between 1.48 and 
$1.87 \mathrm{~cm}^{3} / \mathrm{g}$. In contrast, similar specific volumes ranging between 2.4 and $2.8 \mathrm{~cm}^{3} / \mathrm{g}$ have been reported for starch-based muffins made from $30 \mathrm{~g}$ of batter with incorporation of protein isolates (Shevkani and Singh 2014).

With regard to the EW effect, EW incorporation resulted mainly in a significant decrease in specific volume of muffins containing either CF or CS in comparison with their non-EW counterparts. In the case of CF batters with a smaller quantity of whole egg, the chickpea proteins may antagonize white albumin proteins during mixing, leading eventually to their expulsion from the interface, and preventing bubble expansion during baking.

Table 3 also shows that baked gluten muffin crumb with EW had significantly higher water activity than the rest. This result correlates well with the higher initial moisture content determined in WF (13\%). In turn, muffins made with CF alone and EW showed the lowest water activity, which could be attributed to the greater water absorption ability of chickpea protein. Similar results were reported for CS-based gluten-free muffins enriched with kidney bean, field pea, and amaranth protein isolates (Shevkani and Singh 2014). In muffins without added EW, water activity increased significantly as a result of increasing CS incorporation, which could also be associated with the greater capacity of CF for binding water. Moreover, in most cases the incorporation of EW increased crumb water activity. This could be explained by the higher water content of these muffins.

Color parameters of crust and crumb of CF-based muffins are shown in supplementary Table S3. Both crusts and crumbs made with CF alone became darker than the controls (with significantly lower $L^{*}$ and higher $a^{*}$ values) as increased protein content accelerated Maillard reactions by providing amino acids to react with sugars to produce dark brown substances 
(Shevkani and Singh 2014). The authors just cited also found that crust color became more reddish-brown on incorporation of protein isolates in CS-based muffins. In the present study, the crumb of muffins made from CF alone had the highest yellowness $\left(b^{*}=21.0\right)$, owing to the more orangey color of CF as compared to WF. However, increasing CS content reduced differences between the color parameters of the gluten muffin crust and crumb and those of the muffins made with CF. The 25CF75CS-EW and 25CF75CS muffin crumbs had the highest $L^{*}$ values, reflecting the whiter color of the crumbs prepared with the highest CS content. CS is an almost white powder $\left(L^{*}=97.4\right)$, producing a lighter-colored muffin crumb (Shevkani and Singh 2014).

Color differences $\left(\Delta E^{*}\right)$ were calculated with respect to the $100 \mathrm{WF}$ muffin. The $100 \mathrm{CF}-\mathrm{EW}$ and $100 \mathrm{CF}$ crusts and crumbs also showed significantly higher $\Delta E^{*}$, but in all the CF-based muffins the $\Delta E^{*}$ values decreased as a result of decreasing and increasing protein and CS contents, respectively. Furthermore, for the 100WF-EW, 50CF50CS-EW, 25CF75CS-EW, and 25CF75CS crumbs, the color differences with respect to the 100WF crumb were lower than 3 , implying that these differences would not be perceptible to the human eye (Bodart et al. 2008).

\section{Microstructure of Baked Muffin}

Figures 1 and S1 show SEM and optical micrographs of the muffin crumbs formulated at 0:0, 100:0, and 50:50 CF:CS ratios, either with or without EW. All the baked muffins exhibited irregular distribution of solids (Fig. 1), corresponding to wheat, chickpea, or corn starch granules

and debris of them. These solids are covered by products of the batter baking, consisting of lipids, proteins, and amylose/amylopectin (Guadarrama-Lezama et al. 2016). Control 100WF-EW 
and 100WF crumbs had large and small air bubbles, which gave an appearance of springiness. The 100CF-EW and 100CF muffin crumbs probably had larger bubbles (Fig. S1), which formed tunnels from the base to the surface, indicating that air was lost during formation of the crumb structure (Martínez-Cervera et al. 2012b). On the other hand, they had a moist appearance, with evident crumbling and detaching. A previous study showed that there was an advance of 5 ${ }^{\circ} \mathrm{C}$ in the starting gel point temperature of batters made with $\mathrm{CF}$ alone when compared with that of the gluten one (Alvarez et al. in press). Therefore, a reason for these crumb structures is the early thermosetting of the batters made with CF alone during baking in the oven: as the gas generated by the leavening agent and the water vapor did not have time to expand, they collapsed, which led to the formation of large bubbles [Figure 1 here].

A previous study showed that the viscosity of batter formulated solely with CF was considerably higher than that of other formulations (data not shown). It is possible that, despite release of carbon dioxide by the leavening agent during baking, when the viscosity of the batter is too high the gas cells cannot expand properly. In contrast, upon replacement of half of the CF with CS, 50CF50CS-EW and 50CF50CS crumbs resulted in smoother structures very close to the control ones, with round cavities of various sizes which seemed to be interconnected (Fig. 1). According to Guadarrama-Lezama et al. (2016), the granular-like microstructure of baked sponge cake formulations containing increased CS content was more ordered than that of gluten cake. In the present study, higher starch content favored air retention capacity when compared with higher protein content. It is likely that in the presence of CF alone the starch granules did not swell sufficiently and were too far apart to make contact before the batter set. Therefore, the muffin structure collapsed (Fig. S1). 
With regard to the EW effect, even though muffins with incorporated EW were more consistent than those without EW (Table 2), there was no great difference in appearance between crumb structures with and without added EW. Upon heating, simultaneously with starch swelling, some of the egg proteins denature and coagulate (Wilderjans et al. 2013). Kiosseoglou and Paraskevopoulou (2006) suggested taking into account the possible formation of a mixed protein network of both gluten and egg protein in wheat bakery products. In the present study, samples with incorporated EW contained EW and whole egg at a ratio of 70:30 (Table 1). Therefore, EW and egg yolk proteins probably coagulated together, and gluten (in control muffins) or chickpea (in CF-based muffins) proteins took part in a mixed protein network, explaining the higher hardness observed in the presence of EW (Table 2).

\section{Flash profile, Acceptability, and Consumer Perceptions}

Six different muffins, with CF:CS ratios of 0:0, 100:0, and 50:50 (with and without incorporated EW), were presented simultaneously to the consumers (Figs. 2 and S2) [Figure 2 here]. Each assessor created an average of 8 terms. There were 134 terms originally generated by the consumers, but only the 59 semantically different attributes were considered in the GPA of the FP data (Fig. 3). The first two dimensions accounted for $76.5 \%$ of the total variability. This low variability explained is attributable to the lack of previous experience of the consumers in tasting muffins. Despite this, the samples were perfectly differentiated with regard to the type of flour used, and each of them was located very close to its counterpart with added EW.

The first dimension was a contrast between muffins made with WF or CF alone (Fig. 3), and it involved multivariate perceptions (texture, taste, and appearance), grouping attributes such 
as "height", "size of air pockets", "homogeneous crumb", and "commercial aroma" in the negative part. Muffins made with CF alone showed higher "consistency", "firmness", and "roughness", and were perceived as having darker color (higher brown and yellow colors) than the control muffins. Other attributes placed near $100 \mathrm{CF}$ and $100 \mathrm{CF}-\mathrm{EW}$ samples were related to taste ("chickpea taste" and "chickpea aftertaste"). In these muffins the consumers also detected unpleasant taste or odor. In contrast, the 100WF and 100WF-EW muffins showed characteristics of "home-made" products and better general appearance and "crumb integrity" than the 100CF and 100CF-EW ones [Figure 3 here].

With regard to the second dimension, the 100CF-EW muffin was perceived as stickier, darker, and having higher "aroma" and "taste intensity" than its counterpart without EW. Some taste attributes were also correlated with the first dimension, which opposed "chickpea taste" and "legume taste" (right half) to "sweet", "traditional taste", and "home-made taste" (left half). The second dimension separated the muffins made with CF and CS at 50:50 ratio, with and without added EW, from the other samples. This dimension opposed a series of terms such as "juiciness", "crumbly", and "juicy appearance" (in the upper half of the map, close to 50CF50CS and 50CF50CS-EW) to "dryness", "consistency", and "stickiness". Terms such as "different flour taste", "aftertaste", and "palate roughness" also appeared close to these samples. The second dimension also opposed "yellow color" (top half) to "dark color" and "brown color" (bottom half). Finally, the biplot shows that 100CF and 100CF-EW muffins elicited some unpleasant perceptions, such as "off-taste" and "off-odor".

The consumers also rated the OA, ISC, and PI of the six baked muffins (Table 4). The CF:CS ratio had a significant effect on the scores given by the consumers to the three quality 
indicators. Both OA and PI were significantly lower $(P<0.05)$ in muffins made with CF alone, either with or without EW. The consumers probably did not like the greater firmness and stickiness, the strong chickpea taste, and the perception of off-odors and off-tastes in these muffins. In principle, taste aspects could be improved by adding aromas; however, these muffins also had low "sponginess" and "elasticity" (Fig. 3), which are associated with protein aggregation (Wilderjans et al. 2010) and low starch content [Table 4 here].

In contrast, in terms of liking or OA, the two control gluten muffins rated the highest, although differences in comparison with those prepared with CF and CS at 50:50 ratio were not significant $(P>0.05)$. The highest $\mathrm{PI}$ values were found in the 50CF50CS-EW and 50CF50CS samples, again without significant differences in comparison with the respective controls. These two muffins were perceived as having higher "sponginess" and "elasticity" than the others, desirable muffin properties that are associated with a fresh, elastic, aerated product and linked to high quality (Sanz et al. 2009, Shevkani and Singh 2014).

Muffins made with CF alone had the highest ISC scores (Table 4). This result might be related mainly to the higher scores given by the consumers to texture attributes of these muffins, such as "consistency", "firmness", "roughness", and "stickiness" (Fig. 3), which seemed to trigger expectations of satiating capacity. Therefore, higher OA was related to higher PI. Finally, it is worth nothing that partial whole egg replacement by EW did not influence the scores that the consumers gave for OA, ICS, or PI of the muffins.

\section{Correlations between FP Attributes and Instrumental Measurements}


There are several similarities between the characteristics of the six muffins described by the consumers and their instrumental measurements. Fig. 4A shows the correlation circle between the attributes generated by FP and the instrumental characteristics measured. The first two dimensions explained $70.61 \%$ of the variance and the $R v$ coefficient was 0.86 , reflecting good agreement between sensory space and instrumental parameters. The Rv coefficient has values between 0 and 1, with numbers closer to 1 indicating greater similarity (Escofier and Pagès 1990) [Figure 4 here].

The consumers tended to concentrate mainly on textural attributes and parameters. Sensory "firmness" ( $r=0.88)$ and "hardness" ( $r=0.89)$ were high, and positively correlated with Fmax. However, "hardness" was not correlated with instrumental Hard, indicating that the consumers understood "hardness" and "firmness" differently. "Elastic" was positively correlated with REL $(r=0.79)$ and Spr $(r=0.77)$. Coh was high and positively correlated with the descriptor "sticky in hand" ( $r=0.90)$, but negatively correlated with "crumbly in mouth" ( $r=-0.89)$ and "loose crumb" ( $r=-0.90)$. "Difficult to chew" ( $r=0.89)$ and "palate coating" $(r=0.79)$ were positively correlated with Chew. Specific volume was also high and positively correlated with the descriptor "convex" ( $r=0.96)$, while "crumb color" was positively correlated $(r>0.85)$ with $a^{*}, b^{*}$, and $\Delta E^{*}$ of crumb.

The MFA partial points representation for FP attributes vs instrumental data (Fig. 4B) shows two partial points for each muffin, reflecting sensory and instrumental images. Proximity between these two images can be interpreted as coherence. The two closest images correspond to $100 W F-E W$ and 100CF-EW, reflecting that for these muffins the sensory and instrumental 
characteristics are mutually more coherent. The muffin that presented the greatest discordance between sensory and instrumental data was gluten 100WF.

\section{CONCLUSIONS}

According to the mechanical measurements, total replacement of WF with CF and CS at 50:50 ratio produced muffins that were less elastic and harder or softer than their wheat counterparts, depending on EW incorporation. Results also showed that, with consumers, the spatial configuration obtained by FP was useful to describe the sensory profile of the muffins. In particular, there was a strong correlation between sensory texture attributes and mechanical properties (high regression vector coefficients). The consumers also found that muffins made with a 50:50 ratio, with or without added EW, were very acceptable, similar to gluten ones and they would buy them. There is a possibility of using CS in combination with CF to provide glutenfree muffins with a high ranking for consumer acceptance.

\section{ACKNOWLEDGMENTS}

The authors wish to thank the Spanish Ministry of Economy, Industry and Competitiveness for financial support (AGL2011-28569).

\section{ETHICAL STATEMENTS}

Conflict of Interest: The authors declare that they do not have any conflict of interest.

Ethical Review: The human participants in this study gave their time voluntary for the two sensory sessions. 
Informed Consent: Written informed consent was obtained from all study participants.

\section{REFERENCES}

AGUILAR, N., ALBANELL, E., MIÑARRO, B. and CAPELLAS, M. 2015. Chickpea and tiger nut flours as alternatives to emulsifier and shortening in gluten-free bread. LWT-Food Sci Technol 62, $225-232$.

AlBert, A., VARELA, P., SAlVAdOR, A., HOUGH, G. and FISZMAN, S. 2011. Overcoming the issues in the sensory description of hot served food with a complex texture. Application of $\mathrm{QDA}^{\circledR}$, flash profiling and projective mapping using panels with different degrees of training. Food Qual Pref 22, 463-473.

ALVAREZ-JUBETE, L., ARENDT, E.K. and GALLAGHER, E. 2010. Nutritive value of pseudocereals and their increasing use as functional gluten-free ingredients. Trends Food Sci Technol 21, 106-113.

ALVAREZ, M.D., HERRANZ, B., FUENTES, R., CUESTA, F.J. and Canet, W. Replacement of wheat flour by chickpea flour in muffin batter: effect on rheological properties. J Food Process Eng. doi:10.1111/jfpe.12372.

BAIXAULI, R., SANZ, T., SALVADOR, A. and FISZMAN, S.M. 2008. Textural and colour changes during storage and sensory shelf life of muffins containing resistant starch. Eur Food Res Technol 226, 523-530.

BODART, M., DE PEÑARANDA, R., DENEYER, A. and FlAMANT, G. 2008. Photometry and colorimetry characterisation of materials in daylighting evaluation tools. Build Environ 43, 2046-2058. 
CHANDRA, S., SINGH, S. and KUMARI, D. 2015. Evaluation of functional properties of composite flours and sensorial attributes of composite flour biscuits. J Food Sci Technol 52, 36813688.

CHANG, Y.-W., ALLI, I., MOLINA, A.T., KONISHI, Y. and BOYE, J.I. 2012. Isolation and characterization of chickpea (Cicer arietinum L.) seed protein fractions. Food Bioprocess Technol 5, 618-625.

DIZLEK, H. 2015. Effects of amount of batter in baking cup on muffin quality. Int J Food Eng 11, $629-640$.

ESCOFIER, B. and PAGÈS, P. 1990. Analyses factorielles simples et multiples, second ed. Dunod, París.

guAdarRama-lezama, A.Y., CARRILlo-NAVAS, H., PÉREZ-Alonso, C., VERNON-CARTER, E.J. and ALVAREZ-RAMIREZ, J. 2016. Thermal and rheological properties of sponge cake batters and texture and microstructural characteristics of sponge cake made with native corn starch in partial or total replacement of wheat flour. LWT-Food Sci Technol 70, 46-54.

GULARTE, M.A., DE LA HERA, E., GÓMEZ, M. and ROSELL, C.M. 2012a. Effect of different fibers on batter and gluten-free layer cake properties. LWT-Food Sci Technol 48, 209-214.

GULARTE, M.A., GÓMEZ, M. and ROSELL, C.M. 2012b. Impact of legume flours on quality and in vitro digestibility of starch and protein from gluten-free cakes. Food Bioprocess Technol 5, 3142-3150.

HERRANZ, B., CANET, W., JIMÉNEZ, M.J, FUENTES, R. and ALVAREZ, M.D. 2016. Characterisation of chickpea flour-based gluten-free batters and muffins with added biopolymers: rheological, physical and sensory properties. Int J Food Sci Technol 51, 1087-1098. 
KIOSSEOGLOU, V. and PARASKEVOPOULOU, A. 2006. Eggs. In: Hui YH, Corke H, De Leyn I, Nip W, Cross N, editors. Bakery products: Science and technology Oxford, UK: Blackwell Publishing. p 161-172.

LUO, Y., LI, M., ZHU, K.-X., GUO, X.-N., PENG, W. and ZHOU, H.-M. 2016. Heat-induced interaction between egg white protein and wheat gluten. Food Chem 197, 699-708.

MARCET, I., PAREDES, B. and DÍAZ, M. 2015. Egg yolk granules as low-cholesterol replacer of whole egg yolk in the preparation of gluten-free muffins. LWT-Food Sci Technol 62, 613619.

MARTíneZ-CERVERA, S., SALVAdOR, A., MUguerzA, B., MOULAY, B. and FISZMAN, S.M. 2011. Cocoa fibre and its application as a fat replacer in chocolate muffins. LWT-Food Sci Technol 44, 729-736.

MARTíNEZ-CERVERA, S., SANZ, T., SALVADOR, A. and FISZMAN, S.M. 2012a. Rheological, textural and sensorial properties of low-sucrose muffins reformulated with sucralose/polydextrose. LWT-Food Sci Technol 45, 213-220.

MARTíNEZ-CERVERA, S., DE LA HERA, E., SANZ, T., GÓMEZ, M. and SALVADOR, A. 2012b. Effect of using erythritol as a sucrose replacer in making Spanish muffins incorporating xanthan gum. Food Bioprocess Technol 5, 3203-3216.

MATOS, M.E., SANZ, T. and ROSELL, C.M. 2014. Establishing the function of proteins on the rheological and quality properties of rice based gluten free muffins. Food Hydrocoll 35, 150-158. 
SANZ, T., SALVADOR, A., BAIXAULI, R. and FISZMAN, S.M. 2009. Evaluation of four types of resistant starch in muffins. II. Effects in texture, colour and consumer response. Eur Food Res Technol 229, 197-204.

SHEVKANI, K. and SINGH, N. 2014. Influence of kidney bean, field pea and amaranth protein isolates on the characteristics of starch-based gluten-free muffins. Int J Food Sci Technol 49, 2237-2244.

SHEVKANI, K., KAUR, A., KUMAR, S. and SINGH, N. 2015. Cowpea protein isolates: Functional properties and application in gluten-free rice muffins. LWT-Food Sci Technol 63, 927-933.

SINGH, M., BYARS, J.A. and LIU, S.X. 2015. Navy bean flour particle size and protein content affect cake baking and batter quality. J Food Sci 80, E1229-E1234.

SINGH, J.P., KAUR, A., SHEVKANI, K. and SINGH, N. 2015. Influence of jambolan (Syzygium cumini) and xanthan gum incorporation on the physicochemical and sensory properties of gluten-free eggless rice muffins. Int J Food Sci Technol 50, 1190-1197.

TSATSARAGKOU, K., PAPANTONIOU, M. and Mandala, I. 2015. Rheological, physical, and sensory attributes of gluten-free rice cakes containing resistant starch. J Food Sci 80, E341-E348.

WILDERJANS, E., LUYTS, A., GOESAERT, H., BRIJS, K. and DELCOUR, J.A. 2010. A model approach to starch and protein functionality in a pound cake system. Food Chem 120, 44-51.

WILDERJANS, E., LUYTS, A, BRIJS, K. and DELCOUR, J.A. 2013. Ingredient functionality in batter type cake making. Trends Food Sci Technol 30, 6-15.

WITCZAK, M., ZIOBRO, R., JUSZCZAK, L. and KORUS, J. 2016. Starch and starch derivatives in gluten-free systems - A review. J Cer Sci 67, 45-57.

\section{SUPPORTING INFORMATION}


Additional Supporting Information may be found in the online version of this article:

TABLE S1. TWO-WAY MIXED ANALYSES OF VARIANCE OF TEXTURE PROFILE ANALYSIS (TPA) PARAMETERS OF CF-BASED GLUTEN-FREE BAKED MUFFINS (MAIN EFFECTS: CHICKPEA FLOUR:CORN STARCH (CF:CS) RATIO AND EGG WHITE (EW); 5 CF:CS RATIOS, WITH AND WITHOUT INCORPORATED EW). F AND P VALUES

TABLE S2. TWO-WAY MIXED-ANALYSES OF VARIANCE ON OTHER END-QUALITY CHARACTERISTICS OF GLUTEN-FREE BAKED MUFFINS (MAIN EFFECTS: CHICKPEA FLOUR:CORN STARCH (CF:CS) RATIO AND EGG WHITE (EW); 5 CF:CS RATIOS, WITH AND WITHOUT INCORPORATED EW). F AND P VALUES

TABLE S3. EFFECT OF CHICKPEA FLOUR:CORN STARCH (CF:CS) RATIO AND EGG WHITE (EW) ON THE COLOR PARAMETERS OF THE GLUTEN-FREE BAKED MUFFINS AS COMPARED TO GLUTEN WHEAT FLOUR (WF) BAKED MUFFIN

FIG. S1. OPTICAL IMAGES FOR THE MUFFIN CRUMBS FORMULATED WITH DIFFERENT SELECTED CF:CS RATIOS (0:0, 100:0, AND 50:50) WITH AND WITHOUT ADDED EGG WHITE (EW)

FIG. S2. PHOTOGRAPHS OF CRUSTS OF THE BAKED MUFFINS FORMULATED WITH DIFFERENT SELECTED CF:CS RATIOS (0:0, 100:0, AND 50:50) WITH AND WITHOUT ADDED EGG WHITE (EW) 
TABLE S1. TWO-WAY MIXED ANALYSES OF VARIANCE OF TEXTURE PROFILE ANALYSIS (TPA) PARAMETERS OF CF-BASED GLUTEN-FREE BAKED MUFFINS (MAIN EFFECTS: CHICKPEA FLOUR:CORN STARCH (CF:CS) RATIO AND EGG WHITE (EW); 5 CF:CS RATIOS, WITH AND WITHOUT INCORPORATED EW). $F$ AND $P$ VALUES

\begin{tabular}{lcccccc}
\hline \multirow{2}{*}{ Texture parameter } & \multicolumn{2}{c}{ CF:CS ratio $(\mathrm{df}=4)$} & \multicolumn{2}{c}{ EW $(\mathrm{df}=1)$} & \multicolumn{3}{c}{ CF:CS $\times \mathrm{EW}(\mathrm{df}=4)$} \\
& $F$ value & $P$ value & $F$ value & $P$ value & $F$ value & $P$ value \\
\hline Hard (N) & 50.5 & 0 & 646 & 0 & 30.5 & 0 \\
Spr (-) & 127 & 0 & 52.9 & 0 & 1.63 & 0.186 \\
Coh (-) & 214 & 0 & 12.7 & 0.001 & 15.4 & 0 \\
Chew (N) & 103 & 0 & 477 & 0 & 32.8 & 0 \\
Res (-) & 339 & 0 & 65.9 & 0 & 10.4 & 0 \\
\hline
\end{tabular}

WF: wheat flour; CF: chickpea flour; CS: corn starch; EW: egg white. Hard, Spr, Coh, Chew, and Res: hardness, springiness, cohesiveness, chewiness, and resilience from TPA test. 
TABLE S2. TWO-WAY MIXED-ANALYSES OF VARIANCE ON OTHER END-QUALITY CHARACTERISTICS OF GLUTEN-FREE BAKED MUFFINS (MAIN EFFECTS: CHICKPEA FLOUR:CORN STARCH (CF:CS) RATIO AND EGG WHITE (EW); 5 CF:CS RATIOS, WITH AND WITHOUT INCORPORATED EW). F AND $P$ VALUES

\begin{tabular}{lllllll}
\hline & \multicolumn{3}{l}{$\mathrm{CF}: \mathrm{CS}$ ratio $(\mathrm{df}=4)$} & \multicolumn{2}{l}{$\mathrm{EW}(\mathrm{df}=1)$} & \multicolumn{2}{c}{$\mathrm{CF}: \mathrm{CS}$ ratio $\times \mathrm{EW}(\mathrm{df}=4)$} \\
End-quality characteristic & $F$ value & $P$ value & $F$ value & $P$ value & $F$ value & $P$ value \\
\hline Collapse $(\mathrm{mm})$ & 5.07 & 0.002 & 12.3 & 0.001 & 8.86 & 0.000 \\
Specific volume $\left(\mathrm{cm}^{3} \mathrm{~g}^{-1}\right)$ & 6.55 & 0.002 & 10.7 & 0.004 & 3.17 & 0.036 \\
Water activity & 19.5 & 0.000 & 29.4 & 0.000 & 20.4 & 0.000 \\
\hline Color parameter & $F$ value & $P$ value & $F$ value & $P$ value & $F$ value & $P$ value \\
Crust & & & & & & \\
$L^{*}$ & 76.8 & 0.000 & 5.29 & 0.026 & 10.3 & 0.000 \\
$a^{*}$ & 17.0 & 0.000 & 0.090 & 0.770 & 15.8 & 0.000 \\
$b^{*}$ & 44.4 & 0.000 & 0.000 & 0.973 & 8.44 & 0.000 \\
$\Delta E^{*}$ & 84.1 & 0.000 & 0.010 & 0.934 & 30.0 & 0.000 \\
$C r u m b$ & & & & & & \\
$L^{*}$ & 92.4 & 0.000 & 3.81 & 0.057 & 11.0 & 0.000 \\
$a^{*}$ & 149 & 0.000 & 56.0 & 0.000 & 15.3 & 0.000 \\
$b^{*}$ & 88.7 & 0.000 & 4.13 & 0.047 & 3.01 & 0.026 \\
$\Delta E^{*}$ & 149 & 0.000 & 0.000 & 0.974 & 8.27 & 0.000 \\
\hline
\end{tabular}

WF: wheat flour; CF: chickpea flour; CS: corn starch; EW: egg white; $L^{*}$ : lightness $\left(L^{*}=0\right.$ [black], $L^{*}=100$ [white]), $a^{*}$ : color position between green and red $\left(-a^{*}=\right.$ green, $+a^{*}=$ red); $b^{*}$ : color position between blue and yellow $\left(-b^{*}=\right.$ blue, $+b^{*}=$ yellow $) ; \Delta E^{*}$, total color difference with respect to control gluten $100 \mathrm{WF}$ sample. 
TABLE S3. EFFECT OF CHICKPEA FLOUR:CORN STARCH (CF:CS) RATIO AND EGG WHITE (EW) ON THE COLOR PARAMETERS OF THE GLUTEN-FREE BAKED MUFFINS AS COMPARED TO GLUTEN WHEAT FLOUR (WF) BAKED MUFFIN

\begin{tabular}{|c|c|c|c|c|c|c|c|c|c|c|}
\hline Code & $\begin{array}{l}\text { CF:CS } \\
\text { ratio }\end{array}$ & EW & $\begin{array}{l}\text { Crust } \\
L^{*}\end{array}$ & $a^{*}$ & $b^{*}$ & $\Delta E^{*}$ & $\begin{array}{l}\text { Crumb } \\
L^{*}\end{array}$ & $a^{*}$ & $b^{*}$ & $\Delta E^{*}$ \\
\hline 100WF-EW & $0: 0$ & with & $61.3 \pm 3.26_{a}^{A}$ & $3.91 \pm 2.18_{b}^{B}$ & $22.2 \pm 4.10^{\mathrm{A}, \mathrm{B}}$ & $8.79 \pm 2.81_{a}^{A, B}$ & $66.6 \pm 0.890^{\mathrm{B}}$ & $-1.28 \pm 0.108^{\mathrm{E}}$ & $13.6 \pm 0.373^{\mathrm{E}}$ & $1.96 \pm 0.398^{C}$ \\
\hline 100CF-EW & $100: 0$ & with & $51.1 \pm 0.630^{\mathrm{D}}$ & $9.73 \pm 1.91_{\mathrm{a}}^{\mathrm{A}}$ & $18.9 \pm 0.914^{B, C}$ & $11.0 \pm 1.20_{b}^{A}$ & $63.0 \pm 0.868^{C}$ & $1.03 \pm 0.171_{\mathrm{a}}^{\mathrm{A}}$ & $21.0 \pm 1.06_{\mathrm{a}}^{\mathrm{A}}$ & $6.95 \pm 0.734_{a}^{\mathrm{A}}$ \\
\hline 75CF25CS-EW & $75: 25$ & with & $54.8 \pm 0.872^{\mathrm{B}, \mathrm{C}}{ }_{\mathrm{a}}$ & $9.21 \pm 1.44_{\mathrm{a}}^{\mathrm{A}}$ & $22.1 \pm 0.34^{\mathrm{A}, \mathrm{B}}$ & $6.27 \pm 1.03^{B, C}$ & $62.1 \pm 0.421_{b}^{c}$ & $0.353 \pm 0.178_{\mathrm{a}}^{\mathrm{B}}$ & $19.2 \pm 0.344_{a}^{B}$ & $5.78 \pm 0.401_{\mathrm{a}}^{\mathrm{B}}$ \\
\hline 50CF50CS-EW & $50: 50$ & with & $52.0 \pm 0.721^{C, D}$ & $11.5 \pm 0.572^{\mathrm{A}}$ & $18.5 \pm 1.05^{C}$ & $11.1 \pm 1.25_{b}^{A}$ & $66.3 \pm 0.876_{a}^{B}$ & $-0.422 \pm 0.106_{b}^{C}$ & $17.0 \pm 0.603^{C}{ }_{a}$ & $2.28 \pm 0.631_{\mathrm{a}}^{\mathrm{C}}$ \\
\hline 25CF75CS-EW & $25: 75$ & with & $56.8 \pm 2.47_{a}^{\mathrm{B}}$ & $10.6 \pm 1.50_{\mathrm{a}}^{\mathrm{A}}$ & $24.5 \pm 2.15_{\mathrm{a}}^{\mathrm{A}}$ & $4.39 \pm 2.73^{\mathrm{C}}$ & $68.3 \pm 0.709^{\mathrm{A}}$ & $-0.821 \pm 0.144^{\mathrm{D}}$ & $15.4 \pm 0.550^{\mathrm{D}} \mathrm{a}$ & $2.61 \pm 0.632^{\mathrm{C}} \mathrm{a}$ \\
\hline 100WF & $0: 0$ & without & $57.8 \pm 1.67^{\mathrm{B}}$ & $8.15 \pm 0.923^{B, C}$ & $27.3 \pm 2.93^{\mathrm{A}}$ & $0.000 \pm 0.000_{b}^{D}$ & $65.9 \pm 2.09^{B}$ & $-0.207 \pm 0.085^{c}$ & $14.9 \pm 0.995^{C}$ & $0.000 \pm 0.000_{t}^{D_{t}}$ \\
\hline $100 \mathrm{CF}$ & 100:0 & without & $49.4 \pm 0.55_{b}^{C}$ & $12.0 \pm 0.740^{\mathrm{A}}{ }_{\mathrm{a}}$ & $16.9 \pm 1.08_{b}^{C}$ & $14.0 \pm 1.21_{\mathrm{a}}^{\mathrm{B}}$ & $60.8 \pm 0.505_{b}^{C}$ & $1.03 \pm 0.451_{\mathrm{a}}^{\mathrm{A}}$ & $19.9 \pm 1.50_{\mathrm{a}}^{\mathrm{A}}$ & $7.31 \pm 1.01_{\mathrm{a}}^{\mathrm{A}}$ \\
\hline 75CF25CS & $75: 25$ & without & $55.4 \pm 1.24^{\mathrm{B}}{ }_{\mathrm{a}}$ & $9.82 \pm 1.76_{a}^{A, B}$ & $22.0 \pm 0.961_{\mathrm{a}}^{\mathrm{B}}$ & $6.29 \pm 1.44_{a}^{C}$ & $64.2 \pm 0.869^{\mathrm{B}}{ }_{\mathrm{a}}$ & $0.463 \pm 0.252^{B}$ & $20.3 \pm 1.24_{\mathrm{a}}^{\mathrm{A}}$ & $5.79 \pm 1.07_{\mathrm{a}}^{\mathrm{B}}$ \\
\hline 50CF50CS & $50: 50$ & without & $47.5 \pm 1.68_{b}^{C}$ & $6.79 \pm 1.27_{b}^{C}$ & $14.9 \pm 1.20_{b}^{C}$ & $16.2 \pm 1.95^{\mathrm{A}}$ & $64.4 \pm 0.507_{b}^{B}$ & $0.375 \pm 0.278_{a}^{B}$ & $17.8 \pm 1.38^{\mathrm{B}}{ }_{\mathrm{a}}$ & $3.46 \pm 0.996_{\mathrm{a}}^{\mathrm{C}}$ \\
\hline 25CF75CS & $25: 75$ & without & $60.6 \pm 2.58^{\mathrm{A}}$ & $8.86 \pm 2.00_{a}^{B, C}$ & $25.1 \pm 1.82_{\mathrm{a}}^{\mathrm{A}}$ & $4.86 \pm 1.16^{\mathrm{C}}$ & $68.6 \pm 0.284_{a}^{A}$ & $-0.643 \pm 0.096^{\mathrm{D}}$ & $15.9 \pm 0.671_{a}^{B, C}$ & $2.99 \pm 0.434_{\mathrm{a}}^{\mathrm{C}}$ \\
\hline
\end{tabular}

Values are given as mean $(N=9) \pm$ standard deviation.

${ }^{A-E}$ for each color parameter and EW level mean values without the same letter are significantly different $(P<0.01)$.

$a, b$ for each color parameter and for the same CF:CS ratio mean values between batter with and without added EW are significantly different $(P<0.01)$.

WF: wheat flour; CF: chickpea flour; CS: corn starch; EW: egg white; $L^{*}$ : lightness ( $L^{*}=0$ [black], $L^{*}=100$ [white]),

$a^{*}$ : color position between green and red $\left(-a^{*}=\right.$ green, $+a^{*}=$ red $) ; b^{*}$ : color position between blue and yellow $\left(-b^{*}=\right.$ blue, $+b^{*}=$

yellow); $\Delta E^{*}$, total color difference with respect to control $100 \mathrm{WF}$ sample without added $\mathrm{EW}$ 


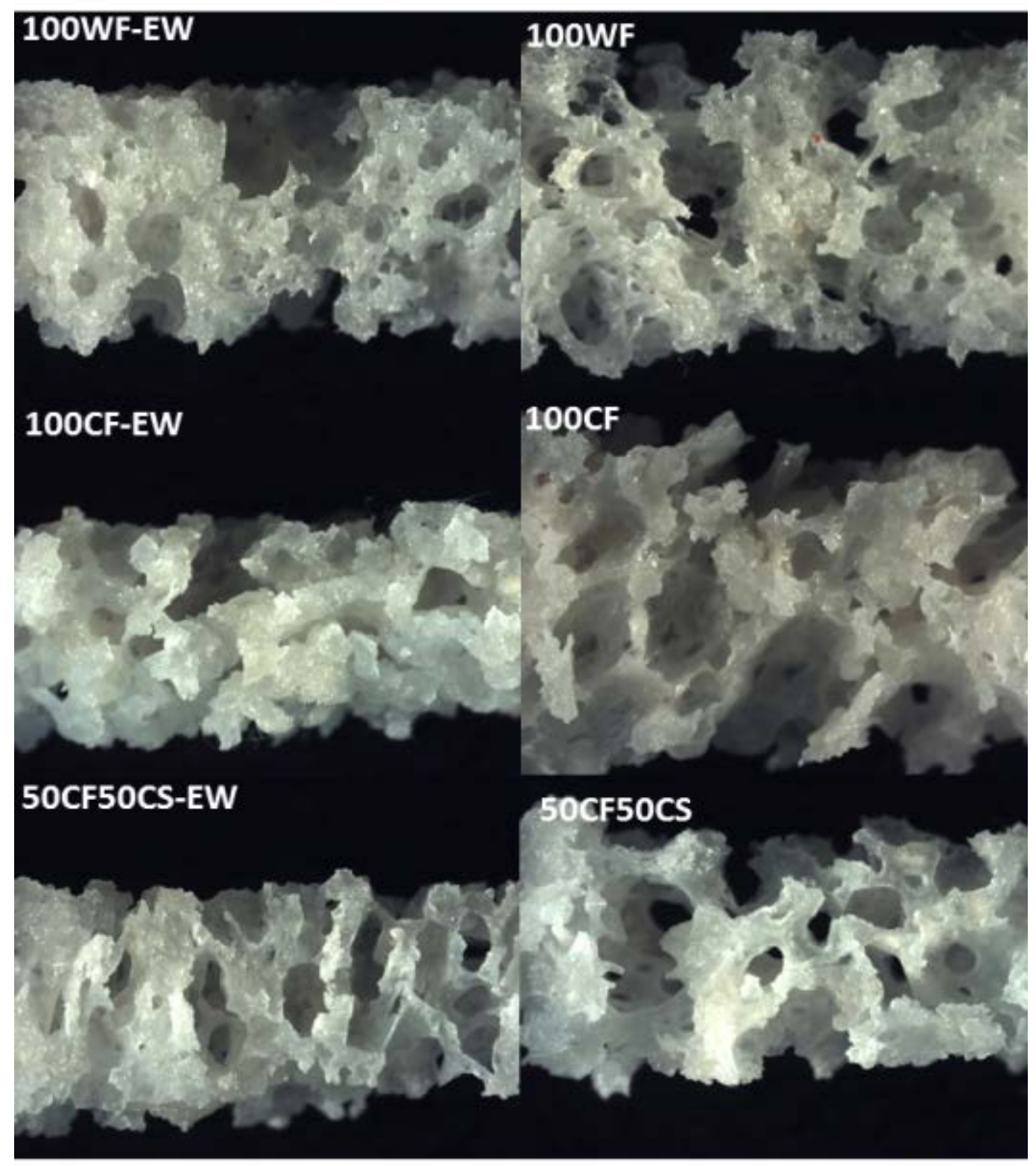

FIG. S1. OPTICAL IMAGES FOR THE MUFFIN CRUMBS FORMULATED WITH DIFFERENT SELECTED CF:CS RATIOS (0:0, 100:0, AND 50:50) WITH AND WITHOUT ADDED EGG WHITE (EW) 


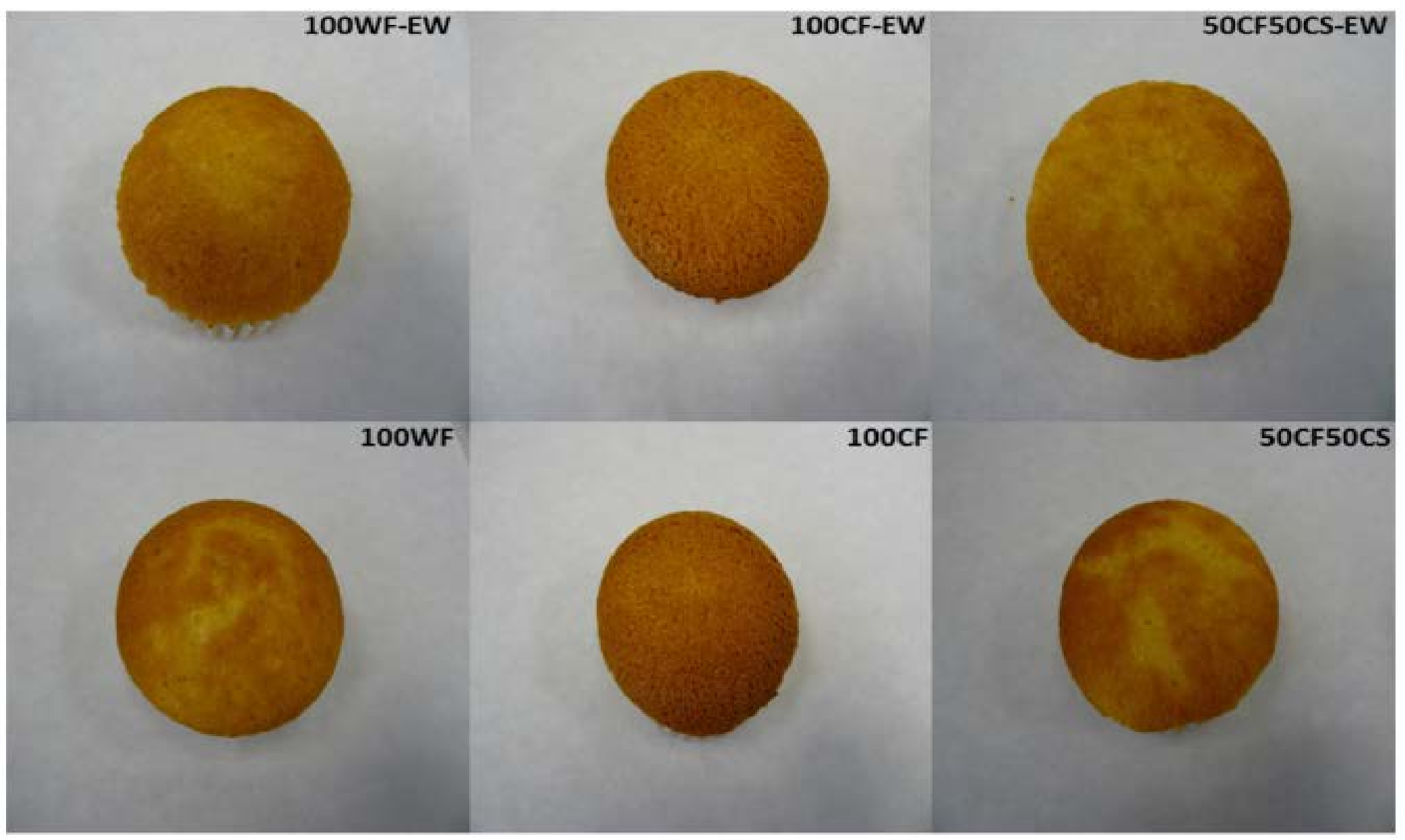

FIG. S2. PHOTOGRAPHS OF CRUSTS OF THE BAKED MUFFINS FORMULATED WITH DIFFERENT SELECTED CF:CS RATIOS (0:0, 100:0, AND 50:50) WITH AND WITHOUT ADDED EGG WHITE (EW) 